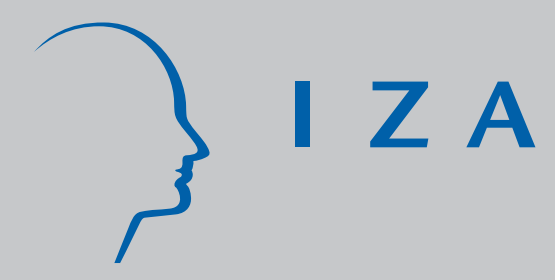

IZA DP No. 947

Potential, Prizes and Performance:

Testing Tournament Theory with

Professional Tennis Data

Uwe Sunde

December 2003 


\title{
Potential, Prizes and Performance: Testing Tournament Theory with Professional Tennis Data
}

\author{
Uwe Sunde \\ IZA Bonn
}

\section{Discussion Paper No. 947 December 2003}

\author{
IZA \\ P.O. Box 7240 \\ D-53072 Bonn \\ Germany \\ Tel.: +49-228-3894-0 \\ Fax: +49-228-3894-210 \\ Email: iza@iza.org
}

This Discussion Paper is issued within the framework of IZA's research area General Labor Economics. Any opinions expressed here are those of the author(s) and not those of the institute. Research disseminated by IZA may include views on policy, but the institute itself takes no institutional policy positions.

The Institute for the Study of Labor (IZA) in Bonn is a local and virtual international research center and a place of communication between science, politics and business. IZA is an independent, nonprofit limited liability company (Gesellschaft mit beschränkter Haftung) supported by Deutsche Post World Net. The center is associated with the University of Bonn and offers a stimulating research environment through its research networks, research support, and visitors and doctoral programs. IZA engages in (i) original and internationally competitive research in all fields of labor economics, (ii) development of policy concepts, and (iii) dissemination of research results and concepts to the interested public. The current research program deals with (1) mobility and flexibility of labor, (2) internationalization of labor markets, (3) welfare state and labor market, (4) labor markets in transition countries, (5) the future of labor, (6) evaluation of labor market policies and projects and (7) general labor economics.

IZA Discussion Papers often represent preliminary work and are circulated to encourage discussion. Citation of such a paper should account for its provisional character. A revised version may be available on the IZA website (www.iza.org) or directly from the author. 


\section{ABSTRACT \\ Potential, Prizes and Performance: Testing Tournament Theory with Professional Tennis Data*}

This paper tests two hypotheses from the theory of elimination tournaments: (i) that uneven tournaments, where the contestants are ex ante heterogeneous, entail lower effort exertion; this is a prediction from agency theory that has not been tested empirically before; and (ii) whether incentives set through prizes matter for effort exertion; this assumption underlies any agency theory about elimination tournaments, and has been empirically tested in other contexts. The evidence obtained with data from professional tennis tournaments supports both the assumption that incentives matter, as well as the theoretical implications concerning uneven tournaments among heterogeneous contestants.

JEL Classification: J41, J33, M12

Keywords: elimination tournaments, uneven tournaments, incentives in tournaments, tennis

Uwe Sunde

IZA

P.O. Box 7240

53072 Bonn

Germany

Tel.: +492283894221

Email: sunde@iza.org

\footnotetext{
* I am grateful to Michael Bognanno, Dan Hamermesh, Christine Harbring, Bob Hutchens, Matthias Kräkel, Jan van Ours and Ken Troske and seminar participants at IZA for helpful discussions, and Georgios Tassoukis for support with the collection of the data.
} 


\section{Introduction}

Apart from selecting the most able workers for particular positions through tournaments, firms frequently use promotion tournaments to provide their workers with incentives. One of the major advantages of tournaments compared to other performance enhancing policies is that already an ordinal outcome measure is sufficient to determine the winner of the tournament. Moreover, tournaments require firms to commit to the promotion of the winner. A rapidly growing economic literature examines the incentive effects implied by the design of promotion tournaments. Prendergast (1999) provides a recent survey of the relevant contributions. According to the basic theoretical framework, pay for a given position in the hierarchy is fixed ex ante by the firm, and increases with the hierarchical level of a job. A group of workers or agents competes for promotion in order to win the prize of a higher salary associated to that position. The relatively best performing candidate wins the tournament and gets the reward of a higher salary. The essential assumption of agency theory in this context is that agents can affect the probability of being promoted and winning the prize through their actions. The prize in form of the (expected) rise in salary when being promoted to the next level, and the possibility to participate in another promotion round, provides incentives to exert effort on the current job: The higher the prize to be won, the larger the incentive for an agent to try to win it. As an implication, Rosen (1986) shows that prizes at the final stage of a hierarchy have to offer an extra reward to maintain performance incentives throughout the entire hierarchy (or tournament), leading to concentration of rewards in top ranks. The theory on elimination tournaments predicts that the total amount of effort exerted in the course of a tournament is highest when the contestants are homogeneous, see Lazear and Rosen (1981), Rosen (1986), and Prendergast (1999). Uneven tournaments, where one contestant is ex ante stronger than the other(s), result in lower effort. Intuitively, the larger the initial disadvantage of a contestant, the more costly it is for him in terms of effort to compensate the handicap. On the other hand, a relatively strong player knows about his head start advantage and can reduce his efforts without endangering his success prospects.

While the assumption of performance incentives through prizes is intuitive, empirical, nonexperimental evidence supporting this assumption is scarce. ${ }^{1}$ Ehrenberg and Bognanno (1990a, 1990b) were the first to use data from golf tournaments in order to test whether incentives matter at all. Overall, they find that the prize money at stake has a significantly positive impact on the concentration and effort players exert, as measured by lower scores needed to complete a

\footnotetext{
${ }^{1}$ There exists evidence from laboratory experiments, starting with Bull, Schotter, and Weigelt (1987).
} 
round. ${ }^{2}$

For the implication that incentives and hence effort should be lower in uneven tournaments with heterogeneous contestants, there exists no empirical evidence at all. While Rosen (1986) merely simulates his model to illustrate the effects of heterogeneity of contestants on effort exertion, Abrevaya (2002) examines the determinants of match winning probabilities of ex ante unequal players in ladder tournaments using data from professional bowling. However, this study does not consider the issue of effort exertion. ${ }^{3}$ Given that, according to the theories proposed, the major motivation for firms to design promotion tournaments is to provide workers with incentives for effort exertion, and given that in reality tournaments among heterogeneous contestants are the rule, while homogenous contestants are the exception, the lack of evidence for the consequences of heterogeneity among contestants calls for an empirical examination of the theoretical predictions. Moreover, knowledge about the incentive effects of heterogeneity is crucial for the optimal design of tournaments in terms of handicaps for heterogeneous players.

This paper provides empirical tests of the theory on tournaments using data from the final two rounds of the most prestigious tennis tournaments for professionals from the Association of Tennis Professionals (ATP). In particular, I test the following two hypotheses: (1) Higher ex ante heterogeneity in the strength of contestants reduces the effort that both players, the favorite and the underdog, exert to win the respective tournament, i.e. the match, and, eventually achieve the highest level, i.e. win the tennis tournament; and (2), higher prize money in a tournament leads to higher effort of the contestants in a tournament, i.e. a tennis match.

Tennis data are particularly suited to investigate incentive effects in uneven tournaments: They perfectly resemble the setting of a two-person tournament, the simplest possible tournament framework allowing for the clearest theoretical predictions. The consideration of evidence for tournaments among only two contestants has several advantages. The strategic interactions in tournaments of only two contestants are clear, no complex issues such as strategic support

${ }^{2}$ The robustness of this finding has subsequently been challenged by Orszag (1994), who shows that, for comparable golf data from a different season, the relationship between prize and scores fails to hold, and attributes the earlier findings to spurious effects mainly driven by weather conditions. Another test for the effects of prize incentives was conducted by Becker and Huselid (1992) for professional NASCAR drivers. Eriksson (1999) and Bognanno (2001) conduct empirical tests of implications of tournament theory using firm-level data and broadly find results supporting theoretical predictions, such as wider pay dispersion enhancing performance or higher prizes being necessary to sustain incentives in larger tournaments.

${ }^{3}$ Experimental studies dealing with uneven tournaments include Bull, Schotter, and Weigelt (1987), Schotter and Weigelt (1992). However, while these experimental studies are either concerned with testing whether individuals' effort choices match theoretical predictions, or with the effects of prize variations on effort in uneven tournaments, none of them directly tests the effects of changes in the extent of heterogeneity on effort. The only related non-experimental empirical evidence coming to mind regards findings that political campaign spending is usually higher in constituencies where the outcome is expected to be closer, see Snyder (1989), Levitt (1994) and the references therein. 
of some, and abatement of other contestants, endogenous coalition formation and so on have to be considered. Sabotage and other undesired actions and side-effects of tournaments are minimized in two-person tournaments, which generally allow for a better supervision than tournaments with many contestants. Moreover, all these problems, including collusion, sabotage etc., can be savely excluded to play a role in tennis data. Two-person elimination tournaments are frequently encountered in reality. Apart from sports, where two-person (or two-team) tournaments are widespread, very often only two contestants or candidates battle for an analogue to promotion in an economic context, for example for positions in top-level management, for the acceptance of a bid in precurement auctions, etc. Moreover, tournaments in reality are virtually always uneven. Hence, evidence for the effects of prizes and heterogeneity on incentives from two-person tournaments is of general interest. Even more so, since the same mechanisms to be empirically investigated here are likely to arise also in tournaments with numerous participants.

The structure of information available in tennis data closely resembles the structure and requirements of information in theoretical models. Prizes are known for each tournament, and on each stage. The strength of players can be inferred from their position in the world ranking prior to the respective tournament, allowing to construct a measure of the heterogeneity of the contestants in a tennis match. Such an objective and permanently up-to-date measure of heterogeneity of contestants such as the ranking information in tennis is generally not available in other data, e.g. from firms, rendering tennis data particularly adequate for testing hypotheses about the effects of heterogeneity in tournaments. Rankings and prizes in the data are predetermined and common knowledge ex ante, that is before a match begins, fulfilling the theoretical requirements and avoiding problems of endogeneity. Moreover, unlike in the context of intermediate-level firm data, tennis tournaments end with the final. Thus, prize money for reaching and/or winning the final is a good proxy for the prize of winning the elimination tournament implied by matches on the two last rounds of tennis tournaments. No dynamic effects or long-term income streams over uncertain time horizons, which are unobservable to the econometrician, but which are crucial in the context of real-world data from firms, have to be taken into account. ${ }^{4}$ Taken together, these features make data from professional tennis particularly suited to test the mentioned issues in tournament theory.

The next section briefly discusses the data, section 3 introduces the empirical framework, and section 4 presents the results. In section 5, two alternative approaches allowing to isolate

\footnotetext{
${ }^{4}$ Of course, incentives to win are also likely to be affected e.g. by the prospects of advertizing contracts, which are more likely to be offered to the winner of a tennis tournament, or players with the best world ranking. However, the value of these contracts to the players is difficult to observe.
} 
the effects of heterogeneity on incentives from other mechanisms at work are discussed, and the robustness of the results is examined. Section 6 concludes.

\section{Data from Professional Tennis Tournaments}

For the empirical analysis, I use data from tournaments for male tennis professionals provided by the (ATP). ${ }^{5}$ The data comprise 156 tournaments for male's singles of the most and second most prestigious categories, Grand Slam and Master Series tournaments, between 1990 and 2002. In particular, the data stem from the four Grand Slam tournaments per year: Australian Open (Melbourne), Roland Garros (Paris), U.S. Open (New York), and Wimbledon. Additionally, the following eight Masters tournaments are included in the data: Cincinnati, Hamburg, Monte Carlo, Montreal, NASDAQ-100 (Miami), Pacific Life (Indian Wells), BNP Paribas (Paris), and Rome. Available tournament information includes soil of the courts, the season and month of the tournament, the size of the tournament in terms of the total number of participating players, and the total prize money to be won in the tournament. For each tournament and year, the data contain detailed match information for the final two rounds, that is for semifinals and finals. By considering only the two final rounds of a tennis tournament, the semifinals and the final, I rule out potential sorting or selection issues implied by initial seeding rules of a tennis tournament, ensuring considerable and random variation in the relative strength of contestants. On the other hand, the data allow to investigate the effects of the stage of the tournament, last but one versus final round, on performance incentives. The available information includes the names of the respective players as well as their current ranking in the ATP Champion's Race, ${ }^{6}$ the numbers of points and sets won by each player in each respective match, and the identity of the winner of each match. Unfortunately, some matches lack information on the games won by each of the players, or they end before the rules would indicate a winner, e.g. due to injury. Eliminating such matches leaves a total of 460 matches comprising 920 observations for individual players. Table 1 contains relevant summary statistics.

\footnotetext{
${ }^{5}$ Data and relevant links are available on the internet under http://www.atptennis.com.

${ }^{6}$ I use rankings in the so-called 'ATP Champion's Race', where players are ranked according to their total points from Grand Slam and Masters tournaments as well as their result in the Masters Cup and their five best results from International Series Tournaments in a given calender year, see http://www.atptennis.com. Missing rankings are replaced by the last available ranking, possibly from the previous year. Note that the lower the rank, the better a player, i.e. the player ranked 1 had the best performance of all tennis professionals over the year.
} 
Table 1: Summary Statistics

\begin{tabular}{|c|c|c|c|c|}
\hline & & Observations $(N)$ & Mean & Std. Dev. \\
\hline Individual Games won & $P$ & 920 & 14.67 & 5.95 \\
\hline $\begin{array}{l}\text { Total Sum of Games won } \\
\text { per Match }\end{array}$ & $\Sigma$ & 460 & 29.34 & 10.02 \\
\hline $\begin{array}{l}\text { Difference in Games won } \\
\text { by Favorite and Underdog }\end{array}$ & $\Delta$ & 460 & 1.73 & 6.19 \\
\hline Absolute difference in Ranks & $H E T$ & 460 & 19.30 & 25.03 \\
\hline Total Prize Money $(\$ 1,000)$ & & 156 & $2,646.24$ & $1,449.48$ \\
\hline $\begin{array}{l}\text { Prize for winning current round } \\
(\$ 1,000)\end{array}$ & & 460 & 246.29 & 153.78 \\
\hline
\end{tabular}

\section{The Empirical Framework}

This section presents the empirical framework used to address the incentive effects of prizes and heterogeneity of contestants, and discusses the determinants of players' effort exertion.

\subsection{The Estimation Set-up}

The empirical analysis is based on the two-contestant model with heterogeneous contestants analyzed by Rosen (1986). At each stage of the tournament, losers are eliminated, while winners obtain a prize and the possibility to participate in the contest on the next level. Since the data from tennis tournaments used cover semifinals and finals, the tournament has two stages or rounds, entailing three contests, or matches. The estimation strategy essentially follows that of previous empirical studies of incentives in the context of sports (golf) tournaments, see Ehrenberg and Bognanno (1990a, 1990b), and Orszag (1994). To test the hypotheses about incentives and heterogeneous contestants on the individual level, I estimate the following basic model :

$$
P_{i m j}=\alpha_{0}+\alpha_{1} H E T_{i m j}+\alpha_{2} P R I Z E_{m j}+\alpha_{3} X_{j}+\varepsilon_{i m j},
$$

where $P_{i m j}$ is the number of games won by player $i$ during match $m$ in tournament $j$ and serves as measure of individual effort exerted by individual $i$. HET is a measure of heterogeneity of the relative strength of the contestants at the outset of the match constructed from the ATP rankings of the contestants prior to the respective tournament. On the level of individual players, heterogeneity is measured by the difference between the player's own rank and the rank of his opponent. Note, that favorites, that is players with a lower ranking than their opponent, are 
associated with negative values for $H E T$, while underdogs exhibit positive values. ${ }^{7} P R I Z E$ is the prize to be won in the respective match $m$ of tournament $j$, for which I use two different specifications. First, I compute the stage prize for semifinals and finals from the respective total prize money offered in the tournament and the rules how it is allocated on the different rounds. This specification reflects the fact that from the theoretical standpoint the difference in the prizes for the winner and the loser of the match are crucial for incentives. However, it neglects, in the case of semifinals, the option value stemming from the possibility of winning an additional prize when winning the match and advancing to the final. To account for this, the second specification uses the total prize money of the tournament and a dummy indicating whether the respective match is a semifinal or a final. ${ }^{8} X_{j}$ are tournament characteristics. In the estimations presented below, I control for tournament specific effects $X$ using a full set of tournament and year dummies throughout. ${ }^{9}$ Note that all regressors are predetermined before the respective tournament or match starts.

Due to the strategical interdependence of the number of games played during a match and for identification reasons, I also construct two alternative measures for effort $E F F_{m j}$ on the level of a match $m$ in tournament $j$ to estimate the model:

$$
E F F_{m j}=\beta_{0}+\beta_{1} H E T_{m j}+\beta_{2} P R I Z E_{m j}+\beta_{3} X_{m} j+\varepsilon_{m j}
$$

The first measure of offort $E F F_{m j}$ is the total number of games played during the match, $\Sigma_{m j}=P_{1 m j}+P_{2 m j}$, where $i=1,2$ are the two contestants, as proxy for total effort. This measure reflects the idea that the harder-fought a match, that is the more effort both players put, the longer the match will last until one player satisfies the conditions for a victory. Consequently, the total number of games played and won can be expected to be higher in matches with both opponents putting higher effort. ${ }^{10}$ Heterogeneity HET on the level of matches is measured as

${ }^{7}$ Using the difference of ranks as heterogeneity neglects that quality differences are likely to be larger among low ranked players, i.e. higher among the top ten than among players ranked 90 to 100. Some of this non-linearity is taken up by adding $H E T^{2}$ or splines as regressors. However, I also construct other allegedly more appropriate measures of heterogeneity as regressors, see the discussion in section 4 below.

8 The distribution of the overall prize money on the diverse rounds of the tournament is similar in all tournaments under consideration. In particular, the prize of winning the final usually accounts for around 16 to 18 percent of the overall prize money, which is twice the prize for reaching the final. The prize for winning the final is paid additionally to the prize for reaching the final. Therefore, both specifications are complementary, the first using variation in prizes, while the second highlights the impact of the higher prizes for winning the final round.

${ }^{9}$ Experiments using data on characteristics such as soil surface, season, month, outdoor dummy, tournament size in terms of the number of participants, and tournament type (grand slam or not) instead of tournament dummies lead to essentially identical results. The same holds for including player dummies, see also section 5.3 and Table 10 below.

${ }^{10}$ Note that this is a direct consequence of the rules of tennis determining the winner as the first contestant reaching a certain threshold of points won. Note also that, even if the outcome of every game is subject to a stochastic component, 'luck' should average-out in the course of a match, as e.g. sides of the court are changed etc. 
the absolute difference in ranks of the two contestants, $\left|R A N K_{1}-R A N K_{2}\right|$.

As further measure of effort on the match level, I consider the difference in games won by the player with an ex ante better ranking, the match favorite, and by the ex ante weaker player, the underdog. This difference is denoted $\Delta_{m j}=P_{1 m j}-P_{2 m j}$, taking contestant 1 as being the favorite, and can be positive as well as negative. Heterogeneity is again measured by the absolute difference in ranks of opponents. The remainder of the section illustrates the appropriateness of this setting to test the hypotheses from tournament theory.

\subsection{Incentives through Prizes}

If (financial) incentives matter, the prize to be won should increase players' effort. The incentive effect in each contest of the tournament rests on the assumption that competitors can affect their winning probability, and thus their probability of winning the prize, by choosing the effort with which they play. In the previous studies on golf, effort is observed in terms of individual scores, and the tournament winner is determined by who requires the smallest number of hits for all rounds. Hence, effort is easily observed in terms of scores, which are obtained by a player independently of other players. In tennis, however, a player's effort is hardly observable independently from the opponent, posing a particular conceptual difficulty for testing effects of prizes on absolute rather than relative performance. Each point that is played can be seen as a zero sum game between the two contestants. In fact, Walker and Wooders (2001) provide evidence from ten tennis matches that the observed serving behavior is consistent with mixed equilibrium strategies of players. Moreover, Klaassen and Magnus (2001) show that the probability of winning a point is not independent from who won the previous point, and that some points are more important to players than others. However, it is intuitive that not only relative, but also absolute efforts of both players affect the observed outcomes in terms of points. While a player affects his probability to win the match by his effort choice, the probability is essentially a function of relative effort. The main assumption in the current analysis is that also the number of games won by a player in a given match, $P$, also depends positively on the players' absolute efforts. To rationalize this assumption, consider the 'technology' for producing points. Games are contested directly between the competitors, every game reflects the outcome of a direct competition. Essentially, the probability of winning a game involves a technology with both players' effort as inputs, just as the probability of winning the match. But the probability of winning a game depends directly on both players' propensity to make an error. Each player's error propensity increases in both efforts, since if both play harder, this involves riskier play, 
attempts to reach otherwise hopeless balls etc. Both players taken together, the probability of winning a point is unaffected by absolute efforts, it just depends on relative effort. Nevertheless, the total number of (forced or unforced) errors increases in the absolute effort levels both players exert. Then, since the match does not end until the threshold for victory is reached, more effort involves more games won by either player, simply because the respective opponent makes more errors. The match winner is the player who is the first to win two or three sets of at least six games, depending on the particular tennis tournament. ${ }^{11}$ Consequently, if the hypothesis about the incentive effects of prizes is true, the prize variable should increase $P$ as well as $\Sigma$, while the effect on $\Delta$ is ambiguous and depends on whether the incentives set by prizes are stronger for the favorite or the underdog.

\subsection{Incentive Effects of Ex Ante Heterogeneity}

Testing the hypothesis about uneven tournaments is a little more intricate than testing for incentive effects of prizes. The problem arises from using the outcome variable 'games won' as measure of effort: On the one hand, agency theory predicts that the total number of games decreases with the heterogeneity of players as measured by the difference of their ATP ranking before the match, since both players exert less effort when they have unequal chances of winning. This is the incentive effect of contestant heterogeneity as predicted by tournament theory. On the other hand, a higher superiority of one player over the other in terms of ability necessarily leads to quicker and clearer decisions, that is fewer games won, even if the efforts of the players are not affected by heterogeneity in their strength. This is a plain capability effect. ${ }^{12}$

Distinguishing capability and incentive effects, is important. From the tournament designer's view, the incentive effect is crucial, since it can be affected by the appropriate incentive scheme,

${ }^{11}$ In tennis, a game consists of at least four balls or points won by a player. After each game, the server changes. For a detailed explanation of the rules of tennis, as well as for which tennis tournaments follow best-of-three or best-of-five sets rules, see http://www.atptennis.com.

12 More formally, suppose the observable outcome variable 'games won' by an individual player, $E$, is a function of unobservable effort $e$, which in turn is a function of the observable variables prize $p$ and the relative individual strength in terms of own rank minus opponent's rank, $h$. Formally, $E=f(e(p, h), p, h)$. Then the effects of $p$ and $h$ on the outcome variable read

$$
\begin{aligned}
& \frac{\partial E}{\partial p}=\frac{\partial f(\cdot)}{\partial p}+\frac{\partial f(\cdot)}{\partial e} \frac{\partial e}{\partial p}>0, \\
& \frac{\partial E}{\partial h}=\frac{\partial f(\cdot)}{\partial h}+\frac{\partial f(\cdot)}{\partial e} \frac{\partial e}{\partial h}<0,
\end{aligned}
$$

respectively. The direct effect of prizes on games won is zero, so any effect of $p$ on $E$ reflects an effort effect, which is supposedly positive: One expects $(\partial f(\cdot) / \partial e)(\partial e / \partial p)>0$, since by assumption, effort increases the points won, $\partial f(\cdot) / \partial e>0$, while effort increases in the prize. On the other hand, heterogeneity affects the observable outcome variable through a direct capability effect, the first term on the right hand side of Equation (4), and an indirect effort effect, the second term, both of negative sign. 
while capability is a datum. From the methodological point of view, testing tournament theory essentially means identifying the incentive effect from the plain capability effect, which is only of secondary interest. In order to identify whether a potential effect of heterogeneity on the outcome variable captures a plain capability effect, or whether it really involves an incentive effect, consider the implications of the two rival explanations. Suppose the latter conjecture were true, and the number of 'games won' were entirely driven by capability differences, not by incentive effects. As a result, larger heterogeneity leads, everything else equal, to more games won by the favorite, and fewer games won by the ex ante weaker player, whose deficient capability reduces his winning probability for every single point. Consequently, $\Delta$ unambiguously increases with player heterogeneity if the capability explanation is appropriate. On the other hand, the overall effect of a larger head start advantage on $\Sigma$ (and $P$ if all players are pooled) is ambiguous. Alternatively, suppose that the incentive explanation were suitable for any heterogeneity effects, and not the capability effect. In equilibrium, the more unequal the chances of winning the match ex ante, the less effort will be exerted by both players, the favorite and the underdog (see Rosen, 1986). Hence, more pronounced heterogeneity unambiguously reduces $P$ and $\Sigma$, while the effect on $\Delta$ is ambiguous. Incentive effects through prizes should survive even if tournaments are uneven. While the following section presents results based on these ideas, section 5 investigates the issue of identifying capability and incentive effects in more detail.

\section{Empirical Results}

This section reports the main findings for the basic specification. Estimation results for $P$ as dependent variable are presented in Table 2. The main results can be briefly summarized as follows. On the individual level, that is for $P$ as regressand, stage prizes exhibit a highly significant and positive effect on effort, regardless of the specification. If total prize money and a dummy indicating the final are used, the prize variation between tournaments exhibits a positive but insignificant effect on effort. However, the incentive effect on effort resulting from playing a final, where the prize to be won is about twice as high as the prize for winning the semifinal, is positive and highly significant. These findings provide evidence in favor of incentive effects of prizes. The results for effort on the level of a match, $\Sigma$, as reported in Table 3 are qualitatively identical to those for effort on the individual level. ${ }^{13}$ Finally, the results for $\Delta$ are contained in Table 4. Consistent with the ambiguous effect of prizes on $\Delta$ predicted by the theory, the regression delivers a slightly negative but insignificant coefficient in both specifications, using

\footnotetext{
${ }^{13}$ Note that, as expected, the incentive effect of prices on $\Sigma$ are about twice as large as those on $P$.
} 
stage prizes or total prizes and dummies for finals.

Next consider the results concerning player heterogeneity interpreted as individual relative weakness. The individual relative disadvantage, measured by a player's own rank prior to the tournament minus the opponent's rank, has a highly significant and negative impact on the $P$ won by a player. This is consistent with both the capability and the incentive story: the better one's position vis-á-vis the opponent, measured by a smaller heterogeneity indicator, the more points the respective player wins. ${ }^{14}$ Moreover, the effect of heterogeneity on individual effort seems to be stronger for lower levels of heterogeneity, as indicated both by the significant negative coefficient for the squared difference in ranks, as well as the significance of the respective spline. ${ }^{15}$ Finally, note that potential measurement error in heterogeneity makes the results even stronger: if the measure of heterogeneity in ranks systematically overstated the true extent of heterogeneity in player quality, as is likely if, e.g. quality differences are concave in rank differences, or if a player reaches the semi-final despite having a very high world ranking due to an excellent momentary shape in the current tournament, the estimated coefficient would be biased toward zero. But, in fact the estimated coefficients for heterogeneity are significantly different from zero in all specifications.

When regressing the total number of games played during a match, $\Sigma$, heterogeneity is measured by the absolute value of the difference in ranks between both contestants. Larger heterogeneity reduces the outcome variable significantly throughout all estimated specifications. This finding is consistent with the incentive effect of heterogeneity on effort, and hence the outcome variable, while the capability argument makes no clear prediction regarding $\Sigma$. The effect seems to exhibit a weak positive interaction with prizes, and is stronger for matches among extremely unequal contestants. Since the capability explanation makes no clear prediction about the effect of heterogeneity on total games won, I take this as evidence for a negative effect of player heterogeneity on effort as predicted by agency theory.

On the other hand, the effect of player heterogeneity on the difference of games won by the favorite and those won by the underdog, $\Delta$, is significant and positive. According to the incentive effect, this effect should be ambiguous, while the strong positive effect is predicted by the larger effect of differences in capability. Moreover, the heterogeneity effect on $\Delta$ appears to

${ }^{14}$ Note that underdogs exhibit positive values of individual relative weakness by definition. The smaller this disadvantage, the more points an underdog wins. On the other hand, the larger the relative strength of a favorite, measured by more negative values of 'relative weakness', the more points he wins.

15 This finding favors the incentive explanation if ranks reflect capability proportionally. However, Klaassen and Magnus (2003) argue that the capability distribution is rather skewed in tennis, in the sense that differences among low ranks have more informative content than equally large differences among high ranks. This issue is taken up again below. 
exhibit a weak concavity. Splines for heterogeneity are not significant on the 5 percent level, but the two splines for small heterogeneity are significant on the 10 percent level, while the null that all spline coefficients are zero can be rejected on the 1 percent level.

To sum up, at first sight both hypotheses to be tested are supported empirically. In particular, the prize effect is strong and consistent with agency theory. Moreover, it seems difficult to find another explanation for such strong effects of prizes on the match outcomes than the one through incentives for effort exertion. However, the negative effect of ex ante heterogeneity in contestants' strength on effort is less clearly identified. Rather, the empirical results seem to be driven by both incentive and capability effects. The next section takes a closer look at this issue.

\section{Does Heterogeneity Really Reduce Incentives?}

In order to identify incentive effects of heterogeneity as opposed to plain capability effects, this section offers two strategies based on the idea that both effects reinforce each other for some players, but tend work in different directions for certain groups of players. The first argument is based on differences in the outcomes for favorites, underdogs, winners and losers. The second uses additional information about the professional experience of individual players and rests on the informational content of their ranking as signal of a player's strength.

\subsection{Different Incentives for Different Players}

Agency theory predicts that heterogeneity decreases the effort of both contestants in a tournament, and regardless of whether a player is favorite or underdog. The capability effect of heterogeneity, on the other hand, affects favorites and underdogs in different ways. While a larger ex ante disadvantage has a larger negative effect on the underdog's observed performance, a larger advantage tends to increase the favorites observed performance. In other words, while capability and incentive effects affect the underdogs' performance in the same direction, both effects operate in different directions when favorites are concerned.

Moreover, in tennis, the effect on the observed measure of effort, games won by an individual, can be expected to be asymmetric, because the rules of the game imply that the number of games won by the winner exhibits less variation than that won by the loser of a match. ${ }^{16}$ Hence, one should expect that the effect of heterogeneity on games won should be downward biased for

\footnotetext{
${ }^{16}$ In particular, games won by winners are censored from below in the current case, since it takes at least 12
} games to be the winner of a match under the best-of-three-sets modus. 
winners relative to that of losers. This is indeed the case as illustrated by estimation results for $P$ presented in the left panel of Table 5. On the other hand, there is no such reason related to the rules of tennis leading one to expect that heterogeneity affects the incentives of favorites and underdogs to a different extent. As the right panel of Table 5 indicates, this is the case, however: Games won by underdogs are significantly lower due to heterogeneity, while favorites' winning points are essentially unaffected by heterogeneity. In other words, the effort exerted by favorites seems to be unaffected by their relative strength, while underdogs win significantly fewer points the larger their disadvantage ex ante. A simple explanation would be that favorites happen to win most of their matches. To test whether this explanation is correct, and to disentangle effects of rules and the relative strength of capability and incentive effects for differnt groups of players, I estimate the model separately for underdogs and favorites who lost their match, and for underdogs and favorites who won their match. The results are depicted in Table 6.

First consider the category of losers, whose number of games won is not constrained by the rules of tennis. In theory, both capability and incentive effects of heterogeneity reduce the number of points won by underdogs. According to the estimation results, the effect of individual relative ex ante weakness is significant and negative for underdogs. The effect is positive, albeit not significant, for favorites. At first sight, this result is surprising: Note that the heterogeneity measure for favorites is negative, the more the larger is their superiority. But a positive coefficient for heterogeneity then means that the larger the predominance of a favorite, the fewer points he scores. This is only consistent with the incentive effect: Similar to underdogs, the capability effect also tends to increase the number of games won by favorites, implying a negative sign for the heterogeneity coefficient. But the incentive effect reduces the number of games won by favorites, implying a positive coefficient. In the current context, the latter effect is apparently stronger, since the number of games won by a favorite increases the less dominant he is in terms of the difference in ranks with respect to the underdog. Simple t-tests show that the difference in the heterogeneity effects on games won between favorites and underdogs is significant.

Repeating the same regressions for winners reveals similar results: the extent of individual relative weakness decreases the number of games won by underdogs, albeit insignificantly, and increases that of favorites significantly. Quantitatively, the effects are smaller than for losers due to the censoring related to the rules of tennis. Estimates of Tobit models with censoring at 12 and 18 points for best-of-three and best-of-five tournaments, respectively, reveals that the heterogeneity coefficients for favorites are even significantly positive, strengthening the point in 
favor of incentive effects. ${ }^{17}$

\subsection{The Informational Content of Rankings}

A second, more subtle strategy to disentangle effort effects and capability effects questions the informativeness of the ranking as indicator of relative strength. So far, a player's ranking was treated as perfect predictor of individual strength. Rankings, which are common knowledge, determine the outcome of the tournament through the players' incentives to play hard, that is the winning prospects of a player in the respective match against a particular opponent. However, the quality of the rank as predictor of relative strength is debatable. Rankings say nothing about particular characteristics that might determine the true heterogeneity of players, and hence rankings might entail little informational content for players. In particular, consider two young tennis professionals clashing in a match. Current rankings might affect their effort very little, since the players know little about each other. Possibly they never played each other before, and thus might be more reluctant to trust the informativeness of their rankings. Rather, both may try to make sure they win the match regardless of the ranking. Alternatively, consider a match between two veteran players who played each other often in the past, and have respective experience about each others' style of play. For them, ranking information is valuable, as they can use it to judge the opponent's current form, and adjust their effort accordingly. Underdogs who just turned professional, on the other hand, might not be affected in their eagerness to win a match by their disadvantage in terms of ranking. Ranking is then not a valuable information to both contestants, and, consequentially, its effect on their effort is little.

To test this hypothesis, I repeat the estimations for $P, \Sigma$ and $\Delta$ separately for two categories of matches. The first category only contains matches between opponents who know each other quite well. In particular, both belong to about the same cohort of professionals, as measured by the date when they turned professional. Their professional experience differs by less than four years. The respective underdog is professional for more than three years. This group, called the 'better known opponents' contains 586 player-observations in 293 matches. The second group contains opponents with the complementary characteristics: Their experience as professional differs by four years or more, and/or the underdog turned professional less than four years ago. This group of 'less known opponents' counts 167 matches involving 334 players. Now note that the ranks of players in both groups are computed by the $A T P$ in exactly the same way. In particular, ranks contain the same amount of information in terms of past performance. This

\footnotetext{
17 Detailed results are availble on request.
} 
implies that capability differences measured by ranks should affect match outcomes regardless of whether opponents are 'better' or 'less' known. However, if heterogeneity affects individual effort exertion, which in turn shapes match outcomes, one would expect that the informational content of the heterogeneity indicator matters. In particular, the games won in matches involving better known opponents should be affected more by rank information than in matches involving less known opponents. Thus, differences in the respective heterogeneity coefficients across groups can be attributed to incentive effects of heterogeneity.

Tables 7 and 8 present the respective estimation results for $P$ on the level of individual players, and $\Sigma$ on the level of matches, respectively. The coefficient of heterogeneity displays no difference between the two groups as far as individual points won, $P$, are concerned. However, the effect of heterogeneity on the total number of games played, $\Sigma$, is larger for the group of opponents with better ex ante knowledge about each other. Moreover, the effect of differences in rankings is significant for this group, while it is not for the group of less known opponents, indicating that ranks contain little valuable information for the respective players. Standard t-tests, however, cannot reject the hypothesis that the effects are the same for both groups of opponents. This can be interpreted as mild evidence for both, the effect of heterogeneity on incentives that is consistent with agency theory, and the fact that the informational content of ranks as indicator of individual strength varies across matches. ${ }^{18}$ Table 9 contains estimation results for $\Delta$. Again, the effect of heterogeneity is positive and significant throughout, but it is larger, albeit insignificantly, for the group of better known agents. While the capability story cannot explain this difference, an explanation through incentives implies that favorites and underdogs slack off by more, the more convinced they are that the difference in ranks correctly reflects the difference in relative strength. ${ }^{19}$

\footnotetext{
18 Arguably, the group of less known opponents contains many young players that only play shortly as professionals and then drop out of the tennis profession again, therefore representing selection of systematically lower types of players. But, apart from the fact that playing in the final two rounds of the major tournaments under investigation here is already a big achievement, the heterogeneity effect on incentives should be even stronger for this group due to stronger capability effects. Thus, the proposed testing strategy is rather conservative in interpreting the results in favor of incentive effects, since the smaller coefficient is unlikely to be merely a selection issue.

${ }^{19}$ As an alternative test of the incentive effects of the informational content of the ranking as indicator of heterogeneity in strength, I run the regressions separately for tournaments early in the year and tournaments late in the year. The information contained in ranks for the latter group is better than for the former group in the sense that it is based on the results of more tournaments. However, the estimation results reveal no difference whatsoever in the coefficients between both groups, indicating that players' effort is less determined by the quality of the ranking indicator, more by their individual interpretation of the ranking in the respective context.
} 


\subsection{Robustness of the Results}

This section discusses the robustness of the previous results with respect to several potential empirical problems. A major concern for the robustness of the results regards the correctness and appropriateness of the measures used for the three core variables in the analysis: Effort, heterogeneity of contestants, and prizes. With respect to effort, the limitations of the three different potential measures, one on the level of individual players and two on the level of matches, as well as their appropriate interpretation are extensively discussed above. Clearly, each measure has its particular weaknesses, but that is one reason why all of them were analyzed. Nevertheless, the revealed patterns indicate a persistent effect of heterogeneity on incentives, and hence outcomes, in the direction predicted by tournament theory. Another concern is the potential endogeneity of effort during the course of a match. That effort is not constant over the course of a match, but varies endogenously has been documented by Klaassen and Magnus (2001). From the perspective of a principal, who designs a tournament in order to provide incentives to exert optimal total effort, such endogeneity is irrelevant. The tournament models whose implications this paper tries to assess empirically treat effort as one-shot decision, not as a dynamic process. Therefore, the global measures of effort considered are perfectly suited to test these theories, potential intra-game endogeneity does neither affect the results nor their interpretation. If anything, endogenous effort changes during the match should tend to weaken the effect of ex ante heterogeneity, since observed patterns may change according to the momentaneous play and strength of players, which is not necessarily related to the rankings.

Another potential problem is the omission of unobserved heterogeneity of players or matches, leading to biased results. To test whether this plays a role, I estimate the models with individual points won during a match, $P$, as dependent variable, also including a full set of player dummies, for a gist of the results see Table 10. The results are qualitatively as before: the effects of prizes and heterogeneity are still significantly positive and negative, respectively, even when individual specific fixed effects are included. ${ }^{20}$

As mentioned before, the use of the (absolute) difference in ATP-ranks as measure of heterogeneity could be problematic, since differences in ability are likely not to be linear in differences of ranks: The ability difference between the best and second best players is likely to be larger than the difference between the players ranked 100 and 101. While adding squared rank dif-

${ }^{20}$ Results for other specifications are available on request. Also including a full set of player dummies in the models for $\Sigma$ and $\Delta$ delivers basically identical results for prize and heterogeneity coefficients as those reported before, in terms of sign, size and significance. Experiments using the number of years as tennis professionals, as well as experience differentials between winners and losers or favorites and underdogs did not change the results on prize and heterogeneity effects either. 
ferences and splines does not alter the qualitative findings, I also construct the heterogeneity measure proposed by Klaassen and Magnus (2003), which is particularly suited in the current context since it takes the pyramid structure of quality prevalent in tennis explicitly into account. The measure is based on the round of the tournament in which a player is expected to lose, and transforms linear ranks into a logarithmic measure of relative strength $D_{i j}$ for player $i$ in match $j$ (vis á vis opponent $j$ ). ${ }^{21}$ Replicating the estimations with this measure instead of the plain difference in ranks delivers qualitatively identical estimates for the heterogeneity coefficients, both in terms of signs and significance, indicating that the results are very robust in this respect, see Table $10 .{ }^{22}$

A further potential concern is that, given data are taken from the last two rounds of a tennis tournament, the results might be affected by selection problems. In particular, the observation of effort measures on the level of finals only for the winners of semi-finals inherently involves a censoring problem, and errors might be correlated among semi-finals and finals. To investigate the robustness of the results, I undertake several experiments. First, I discard all data for semifinals and estimate the model only for data from finals. The results, regardless of the dependent variable used, exhibit a very similar pattern: Coefficients for the prize variable are insignificant, presumably as a consequence of little variation in prizes across tournaments and time. The results for heterogeneity, on the other hand, are essentially identical to those obtained for the entire sample. ${ }^{23}$ As a second robustness check, I construct and estimate a selection model on the level of individual players. In particular, I treat the observations of individual points won, $P$, as censored observations on the level of finals, depending on whether the respective player won a semi-final or not. The selection on the level of semi-finals is modeled following Klaassen and Magnus (2003) as a binary choice model, with the heterogeneity of the respective opponents in the semi-final, as well as the differences in the prizes for winning the semi-final and winning the final as explanatory variables. The results for the baseline specification are shown in the last two columns of Table 10. Adding tournament and year dummies as explanatory variables

${ }^{21}$ The measure of 'expected terminal round for player $i$ ' with ATP-ranking $R A N K_{i}$ is given by

$$
R_{i}=7-\log _{2}\left(R A N K_{i}\right) .
$$

Note that the better ranked a player is, the later he is expected to drop out of the tournament, implying a higher measure $R_{i}$. The measure of relative strength of $i$ in a match against $j$ is then computed as $D_{i j}=R_{i}-R_{j}$. Given that higher $R$-measures indicate better players, $D$ allegedly has a positive effect on individual effort, as opposed to the difference of plain ranks, where the opposite is true.

22 The coefficient estimates for this alternative heterogeneity measure are even consistently larger in absolute terms and exhibit higher levels of significance in all models, and for all three measures of effort.

${ }^{23}$ In particular, coefficients of heterogeneity in the models for $P, \Sigma$ and $\Delta$ are negative and highly significant, negative and marginally significant, and positive and significant, respectively. Detailed results are available upon request. 
in the selection equation leads to essentially identical results. Whatever specification is taken, the inverse Mill's ratio from selection does not significantly affect the coefficients obtained for the final stage regressions. The coefficient estimates for the variables of interest are essentially the same as those obtained with the regressions for finals only. In other words, selection seems to play no role for the results obtained in the previous sections. ${ }^{24}$

Finally, the concepts of prizes used seem less problematic, since the respective sums of prize money used as regressor indeed measure the pecuniary reward of winning a (stage) tournament, i.e. match, just as required for being consistent with the theoretical counterpart. Interestingly, as indicated by the estimations for finals, variation in prizes over the course of a tournament, that is the option value of being able to win the 'jack pot' in terms of the final winner's prize, seems to primarily determine incentives, as predicted by Rosen (1986). Variation in prizes across tournaments, on the other hand, has an insignificant effect on effort.

\section{Concluding Remarks}

This paper tests two hypotheses from tournament theory using data from professional tennis tournaments. These data are particularly suited for validating the assumption that prizes affect the effort players exert during the tournament through the respective incentives to win the tournament, and for testing whether ex ante heterogeneity in terms of opponents' ranking decreases their efforts.

The results reveal that incentives in terms of prizes promote performance in terms of the number of games won by individual players and total effort exerted during a match, as measured by the total number of games played. In particular, higher stage prizes, and the substantially higher prizes to be won in finals as compared to semifinals significantly promote effort exertion. This confirms previous empirical findings.

The second and major novel finding of this paper is that the extent to which a match between two opponents is biased in terms of their initial relative strength indeed determines the match outcomes through affecting effort exertion. In particular, the number of games won by a player, the total number of games played, and the difference in games won by the favorite

${ }^{24}$ The same is true when player dummies are included. For comparison, I also estimate the the probability that a player wins a particular match using the heterogeneity measure $D_{i j}$ as defined in footnote 21 at the beginning of the match as only explanatory variable, replicating the forecasting method of the winner of a tennis match at the outset of the match proposed by Klaassen and Magnus (2003). While they use data for all matches played by males at Wimbledon between 1992 and 1995, I use data on semi-finals and finals of various tournaments between 1990 and 2002 as described in section 2 . The logit coefficients for $D$ are almost identical to the coefficients they find, even though obtained on an entirely different data set. Detailed results are available upon request. 
and the underdog are affected by contestants' ranking prior to the match both through a plain capability effect as well as through an incentive effect. Both effects can be disentangled by separately investigating different categories of players. While both effects reinforce each other when underdogs are concerned, capability and incentive effects work against each other for favorites. The significantly different results for underdogs and favorites provide evidence for a negative effect of player heterogeneity on their incentives. Moreover, incentive effects of heterogeneity as measured by relative rankings prior to the match are stronger, the more valuable the information about heterogeneity is. In matches with about equally experienced opponents, who are already professionals for some time, rankings provide a good indicator about their opponents current shape. Consequently, in these matches, the impact of heterogeneity measured by rank differences on individual and total games won, is larger than in matches with opponents who have less experience with each other. Extensive robustness checks confirm the findings. 


\section{References}

AbrevayA, J. (2002): "Ladder Tournaments and Underdogs: Lessons from Professional Bowling," Journal of Economic Behavior and Organization, 47(1), 87-101.

Becker, B., AND M. Huselid (1992): "The Incentive Effects of Tournament Compensation Systems," Administrative Science Quarterly, 37, 336-350.

Bognanno, M. L. (2001): "Corporate Tournaments," Journal of Labor Economics, 19(2), $290-315$.

Bull, C., A. Schotter, and K. Weigelt (1987): "Tournaments and Piece Rates: An Experimental Study," Journal of Political Economy, 95(1), 1-33.

Ehrenberg, R. G., and M. L. Bognanno (1990a): "Do Tournaments Have Incentive Effects?," Journal of Political Economy, 98(6), 1307-1324.

(1990b): "The Incentive Effects of Tournaments Revisited: Evidence from the European PGA Tour," Industrial and Labor Relations Review, 43(Suppl.), 74-88.

Eriksson, T. (1999): "Executive Compensation and Tournament Theory: Empirical Tests on Danish Data," Journal of Labor Economics, 17(2), 262-280.

Klaassen, F. J., and J. R. Magnus (2001): "Are Points in Tennis Independent and Identically Distributed? Evidence from a Dynamic Binary Panel Data Model," Journal of the American Statistical Association, 96, 500-509.

(2003): "Forecasting the Winner of a Tennis Match," European Journal of Operational Research, 148, 257-267.

Lazear, E., And S. Rosen (1981): "Rank Order Tournaments as Optimal Labor Contracts," Journal of Political Economy, 89(5), 841-864.

LEvitT, S. D. (1994): "Using Repeat Challengers to Estimate the Effect of Campaign Spending on Election Outcomes in the U.S. House," Journal of Political Economy, 102(4), 777-798.

Orszag, J. M. (1994): "A New Look at Incentive Effects and Golf Tournaments," Economics Letters, 46(1), 77-88.

Prendergast, C. (1999): "The Provision of Incentives in Firms," Journal of Economic Literature, XXXVII(1), 7-63.

Rosen, S. (1986): "Prizes and Incentives in Elimination Tournaments," American Economic Review, 76(4), 701-715.

Schotter, A., And K. Weigelt (1992): "Asymmetric Tournaments, Equal Opportunity Laws, and Affirmative Action: Some Experimental Results," Quarterly Journal of Economics, 107(2), 511-592.

Snyder, J. M. (1989): "Election Goals and the Allocation of Campaign Resources," Econometrica, 57(3), 637-660.

Walker, M., And J. Wooders (2001): "Minimax Play at Wimbledon," American Economic Review, 91(5), 1521-38. 
Table 2: Incentives and Performance: Individuals

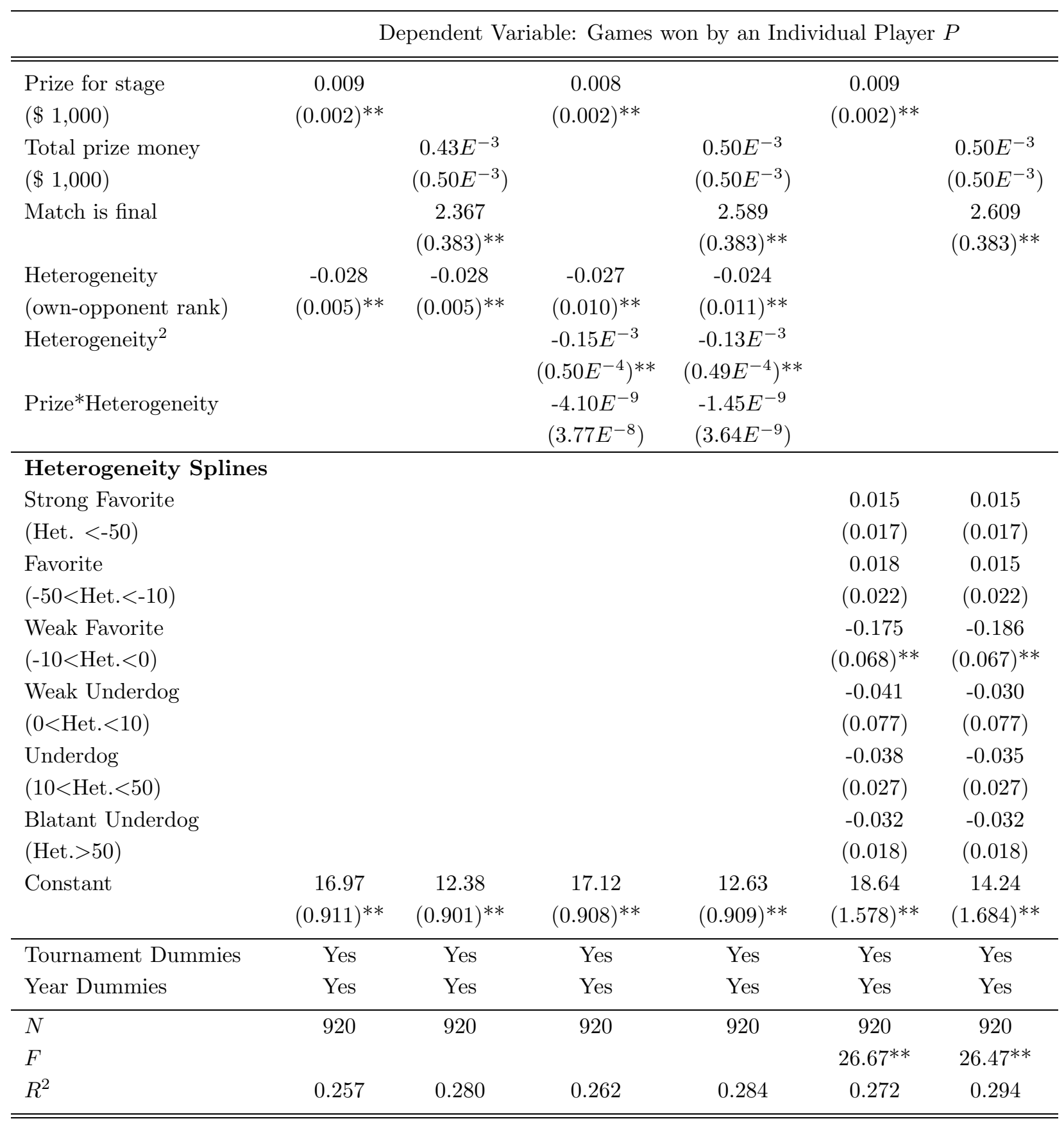

Notes: Robust standard errors in parentheses. ${ }^{* *}$ Coefficient significant at the 1-\%-level. ${ }^{*}$ Coefficient significant at the 5-\%-level. F-tests for the null that all splines are zero. Degrees of freedom: $(1 ; 888)$, and $(1 ; 889)$, respectively. 
Table 3: Incentives and Performance: Matches $(\Sigma)$

\begin{tabular}{|c|c|c|c|c|c|c|}
\hline \multirow[b]{2}{*}{ Prize for stage } & \multicolumn{2}{|c|}{ it V } & \multicolumn{4}{|c|}{ Total number of games played during a match, $\Sigma$} \\
\hline & 0.017 & & 0.012 & & 0.017 & \\
\hline$(\$ 1,000)$ & $(0.005)^{* *}$ & & $(0.005)^{*}$ & & $(0.005)^{* *}$ & \\
\hline Total prize money & & 0.001 & & $0.70 E^{-3}$ & & 0.001 \\
\hline$(\$ 1,000)$ & & $(0.001)$ & & $(0.001)$ & & $(0.001)$ \\
\hline Match is final & & 5.165 & & 5.124 & & 5.301 \\
\hline & & $(0.875)^{* *}$ & & $(0.876)^{* *}$ & & $(0.883)^{* *}$ \\
\hline Heterogeneity & -0.038 & -0.034 & -0.092 & -0.047 & & \\
\hline (own-opponent rank) & $(0.013)^{* *}$ & $(0.013)^{*}$ & $(0.038)^{*}$ & $(0.036)$ & & \\
\hline Heterogeneity $^{2}$ & & & $-0.24 E^{-4}$ & $-0.13 E^{-3}$ & & \\
\hline & & & $\left(2.3 E^{-3}\right)$ & $\left(0.24 E^{-3}\right)$ & & \\
\hline Prize*Heterogeneity & & & $2.44 E^{-7}$ & $9.96 E^{-9}$ & & \\
\hline & & & $\left(1.03 E^{-7}\right)^{*}$ & $\left(1.05 E^{-8}\right)$ & & \\
\hline \multicolumn{7}{|l|}{ Heterogeneity Splines } \\
\hline Close Match & & & & & 0.446 & 0.555 \\
\hline$(0<\mid$ Het. $\mid<5)$ & & & & & $(0.372)$ & $(0.368)$ \\
\hline Unequal Match & & & & & -0.155 & -0.163 \\
\hline$(5<\mid$ Het. $\mid<15)$ & & & & & $(0.139)$ & $(0.136)$ \\
\hline Unequal Match & & & & & -0.009 & $-0.31 E^{-3}$ \\
\hline$(15<\mid$ Het. $\mid<50)$ & & & & & $(0.052)$ & $(0.050)$ \\
\hline Extremely Unequal Match & & & & & -0.058 & -0.059 \\
\hline$(\mid$ Het. $\mid>50)$ & & & & & $(0.029)^{*}$ & $(0.030)^{* *}$ \\
\hline \multirow[t]{2}{*}{ Constant } & 28.38 & 27.38 & 29.80 & 31.17 & 26.71 & 26.59 \\
\hline & $(3.148)^{* *}$ & $(6.797)^{* *}$ & $(3.160)^{* *}$ & $(7.227)^{* *}$ & $(4.483)^{* *}$ & $(6.842)^{* *}$ \\
\hline Tournament Dummies & Yes & Yes & Yes & Yes & Yes & Yes \\
\hline Year Dummies & Yes & Yes & Yes & Yes & Yes & Yes \\
\hline$N$ & 460 & 460 & 460 & 460 & 460 & 460 \\
\hline$F$ & & & & & 2.16 & 3.02 \\
\hline$R^{2}$ & 0.340 & 0.371 & 0.347 & 0.372 & 0.343 & 0.375 \\
\hline
\end{tabular}

Notes: Robust standard errors in parentheses. ${ }^{* *}$ Coefficient significant at the $1-\%$-level. ${ }^{*}$ Coefficient significant at the 5-\%-level. F-tests for the null that all splines are zero. Degrees of freedom: $(1 ; 431)$, and $(1 ; 430)$, respectively. 
Table 4: Incentives and Performance: Matches $(\Delta)$

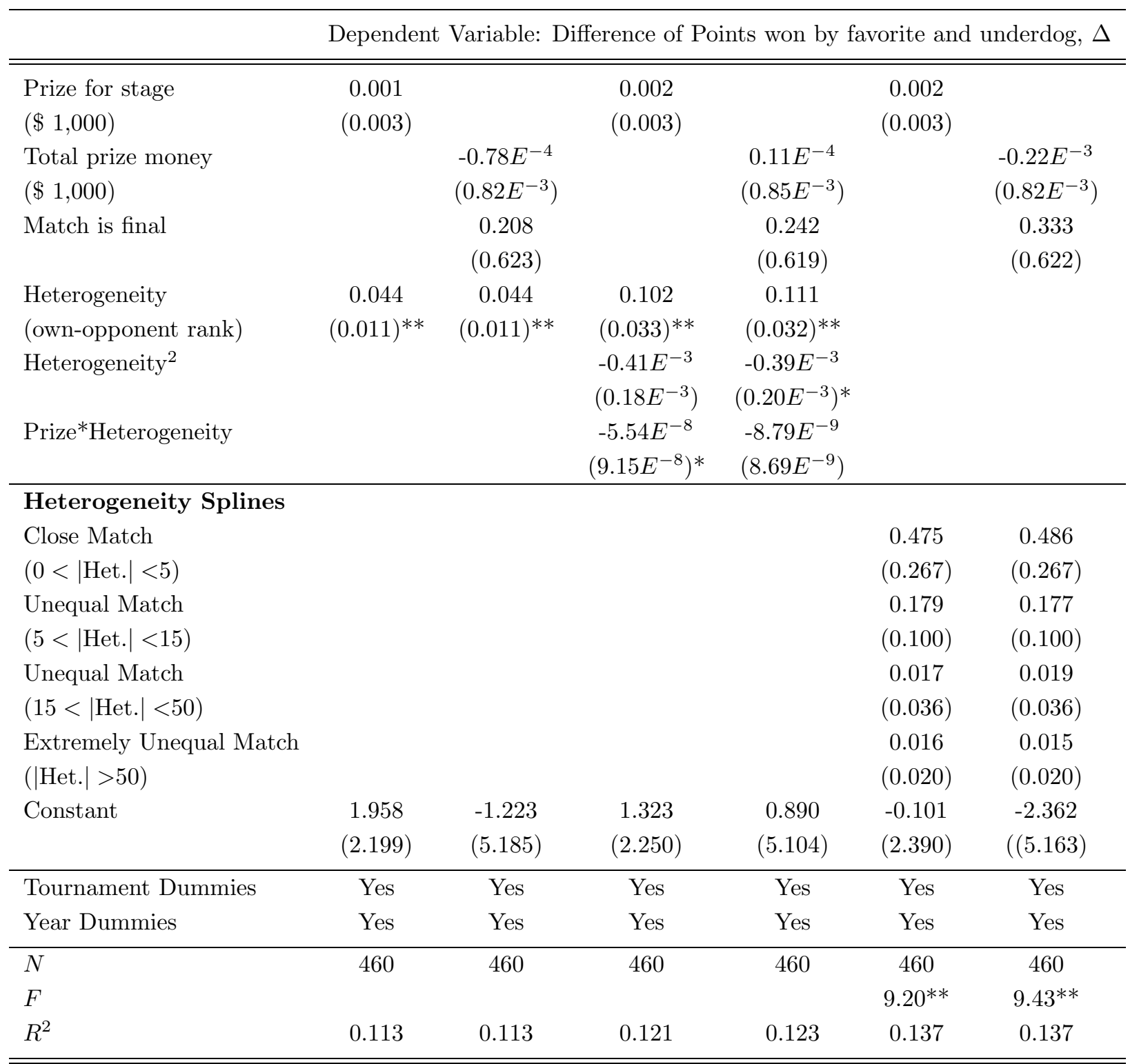

Notes: Robust standard errors in parentheses. ${ }^{* *}$ Coefficient significant at the $1-\%$-level. ${ }^{*}$ Coefficient significant at the 5-\%-level. F-tests for the null that all splines are zero. Degrees of freedom: $(1 ; 431)$, and $(1 ; 430)$, respectively. 


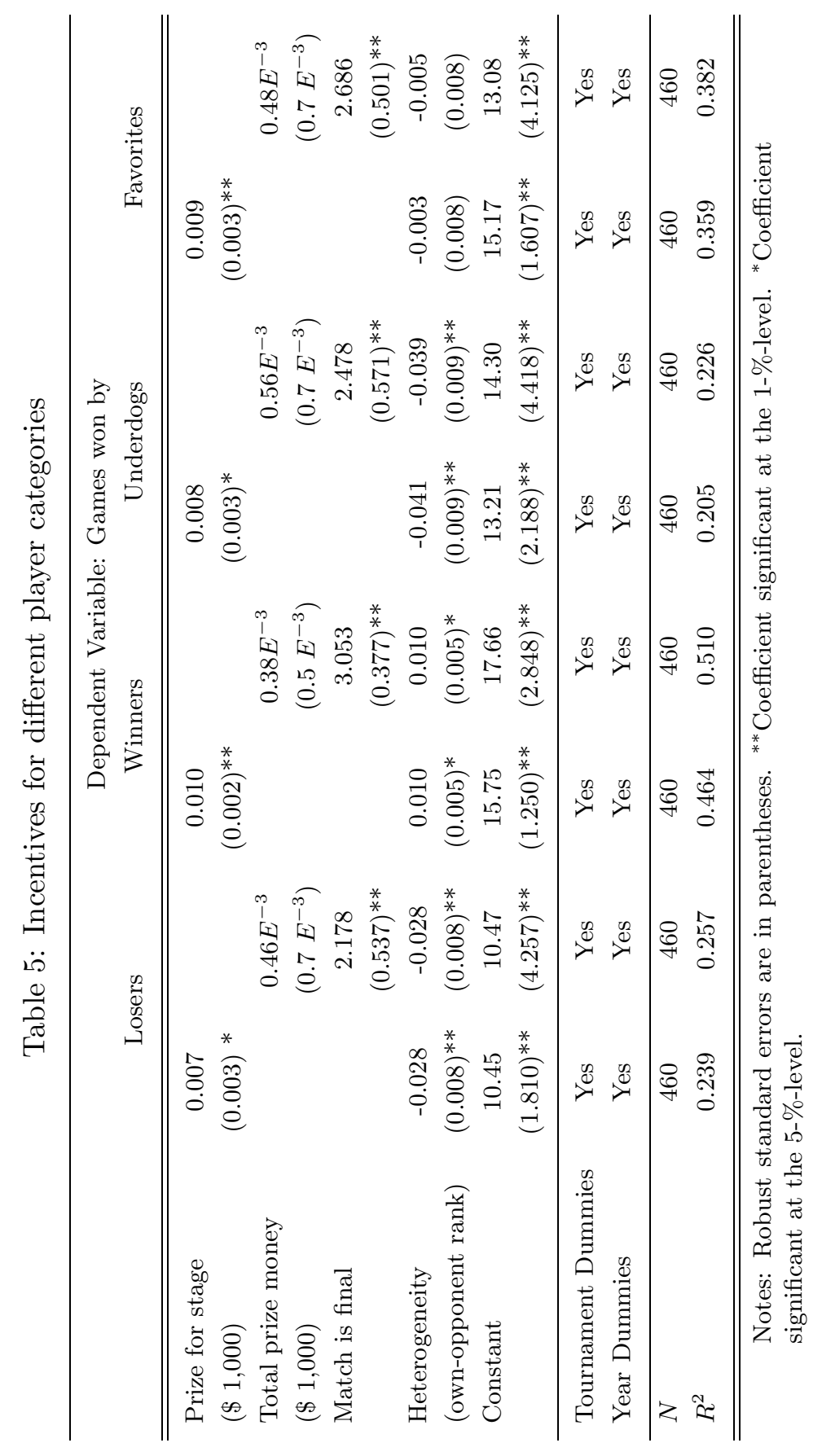




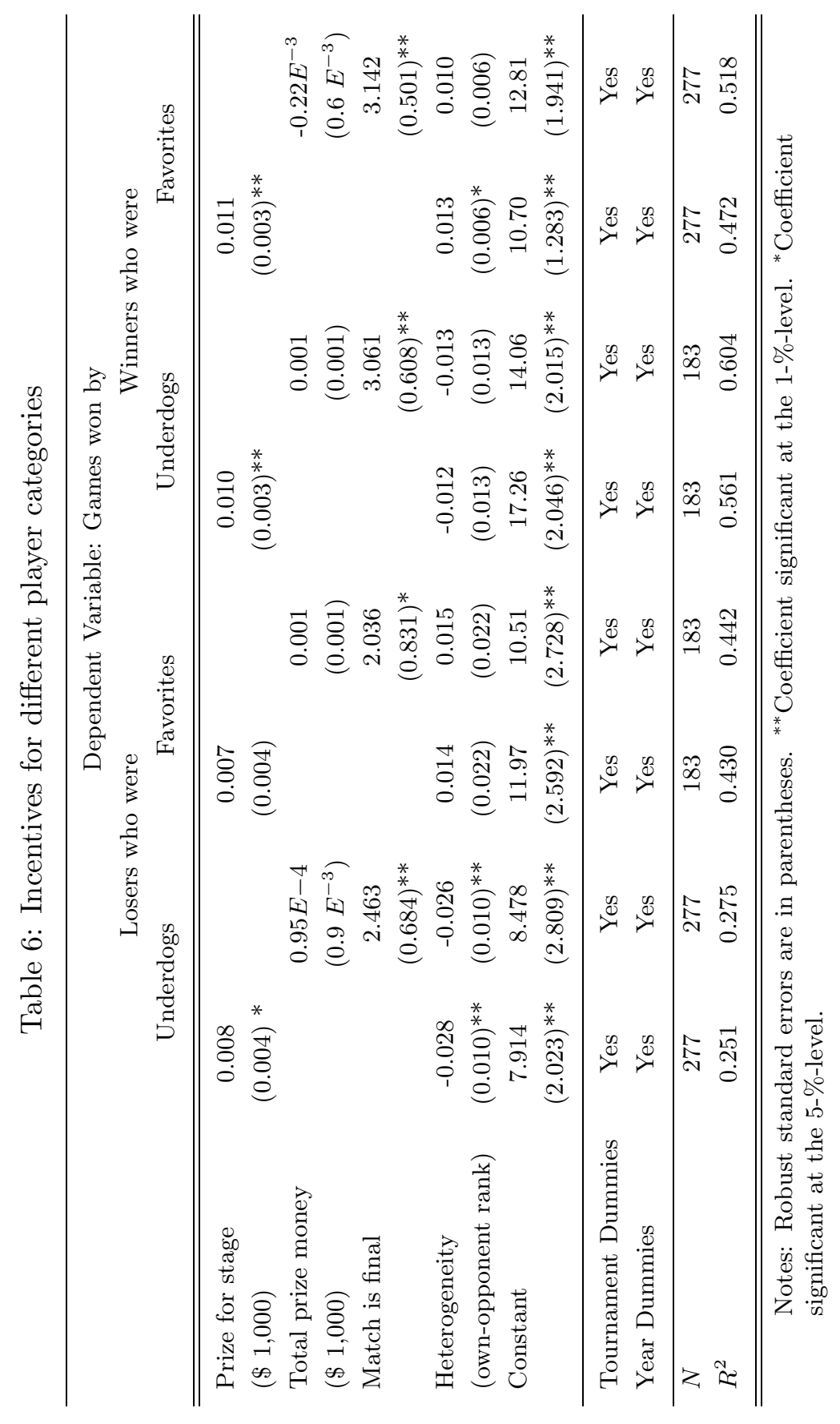


Table 7: Incentives and Ranking Significance: Individuals

Dependent Variable: Individual Points $P$

Better known opponent Less known opponent

\begin{tabular}{lcccc}
\hline \hline $\begin{array}{l}\text { Prize for stage } \\
(\$ 1,000)\end{array}$ & 0.007 & \multicolumn{3}{c}{0.009} \\
Total prize money & $(0.002)^{* *}$ & \multicolumn{2}{c}{$(0.004)^{* *}$} & \\
$(\$ 1,000)$ & & 0.001 & $0.52 E^{-3}$ \\
Match is final & $\left(0.7 E^{-3}\right)$ & & $\left(0.8 E^{-3}\right.$ \\
& & 2.062 & 3.045 \\
Heterogeneity & $(0.458)^{* *}$ & & $(0.715)^{* *}$ \\
(own-opponent rank) & $(0.008)^{* *}$ & $(0.008)^{* *}$ & $(0.007)^{* *}$ & $(0.006)^{* *}$ \\
Constant & 17.46 & 13.01 & 11.07 & 9.216 \\
& $(1.433)^{* *}$ & $(3.877)^{* *}$ & $(2.053)^{* *}$ & $(2.262)^{* *}$ \\
\hline Tournament Dummies & Yes & Yes & Yes & Yes \\
Year Dummies & Yes & Yes & Yes & Yes \\
\hline$N$ & 586 & 586 & 334 & 334 \\
$R^{2}$ & 0.304 & 0.321 & 0.262 & 0.291 \\
\hline \hline
\end{tabular}

Notes: Observations grouped with regards to Information about the opponent. Group "Better known opponent" only includes matches with both players having about equal experience as professional (less than 4 years difference) and the underdog is professional for more than 3 years. Group "Less Known Opponent" is the complementary group. Robust standard errors are in parentheses. ${ }^{* *}$ Coefficient significant at the $1 \%$-level. ${ }^{*}$ Coefficient significant at the $5 \%$ level. 
Table 8: Incentives and Ranking Significance: Matches $(\Sigma)$

\begin{tabular}{lcccc}
\hline & \multicolumn{3}{c}{ Dependent Variable: Total Points, $\Sigma$} \\
& Better known opponent & Less known opponent \\
\hline \hline Prize for stage & 0.014 & \multicolumn{3}{c}{0.018} \\
$(\$ 1,000)$ & $(0.005)^{* *}$ & & $(0.010)^{* *}$ & \\
Total prize money & & 0.002 & & 0.001 \\
$(\$ 1,000)$ & & $(0.002)$ & & $(0.002)$ \\
Match is final & & 4.040 & & 5.890 \\
& & $(1.018)^{* *}$ & & $(1.700)^{* *}$ \\
Heterogeneity & -0.048 & -0.049 & -0.035 & -0.031 \\
(own-opponent rank) & $(0.023)^{*}$ & $(0.023)^{*}$ & $(0.018)^{* *}$ & $(0.018)$ \\
Constant & 36.69 & 24.96 & 17.93 & 18.58 \\
& $(3.482)^{* *}$ & $(8.558)^{* *}$ & $(4.019)^{* *}$ & $(1.909)^{* *}$ \\
\hline Tournament Dummies & Yes & Yes & Yes & Yes \\
Year Dummies & Yes & Yes & Yes & Yes \\
\hline$N$ & 293 & 293 & 167 & 167 \\
$R^{2}$ & 0.416 & 0.441 & 0.334 & 0.372 \\
\hline \hline
\end{tabular}

Notes: Dependent variable is the sum of all points played during a given match. Observations grouped with regards to Information about the opponent. Group "Better known opponent" only includes matches with both players having about equal experience as professional (less than 4 years difference) and the underdog is professional for more than 3 years. Group "Less Known Opponent" is the complementary group. Robust standard errors are in parentheses. ${ }^{* *}$ Coefficient significant at the $1 \%$-level. ${ }^{*}$ Coefficient significant at the $5 \%$-level. 
Table 9: Incentives and Ranking Significance: Matches $(\Delta)$

\begin{tabular}{lcccc}
\hline & \multicolumn{3}{c}{ Dependent Variable: Point Difference, $\Delta$} \\
& Better known opponent & Less known opponent \\
\hline \hline Prize for stage & 0.005 & & -0.004 & \\
$(\$ 1,000)$ & $(0.003)$ & & $(0.006)$ & \\
Total prize money & & $-0.20 E^{-3}$ & & -0.001 \\
$(\$ 1,000)$ & $(0.001)$ & & $(0.001)$ \\
Match is final & & 0.888 & & -0.342 \\
& & $(0.759)$ & & $(1.159)$ \\
Heterogeneity & 0.058 & 0.060 & 0.033 & 0.034 \\
(own-opponent rank) & $(0.021)^{* *}$ & $(0.021)^{* *}$ & $(0.012)^{* *}$ & $(0.012)^{* *}$ \\
Constant & 0.451 & -1.452 & 9.523 & 10.41 \\
& $(2.160)$ & $(6.542)$ & $(2.816)^{* *}$ & $(3.480)^{* *}$ \\
\hline Tournament Dummies & Yes & Yes & Yes & Yes \\
Year Dummies & Yes & Yes & Yes & Yes \\
\hline$N$ & 293 & 293 & 167 & 167 \\
$R^{2}$ & 0.157 & 0.154 & 0.220 & 0.219 \\
\hline \hline
\end{tabular}

Notes: Dependent variable is the difference of points won by favorite and underdog during a given match. Observations grouped with regards to Information about the opponent. Group "Better known opponent" only includes matches with both players having about equal experience as professional (less than 4 years difference) and the underdog is professional for more than 3 years. Group "Less Known Opponent" is the complementary group. Robust standard errors are in parentheses. ${ }^{* *}$ Coefficient significant at the $1 \%$-level. ${ }^{*}$ Coefficient significant at the $5 \%$-level. 
Table 10: Incentives and Performance: Some Robustness Results

\begin{tabular}{|c|c|c|c|c|c|c|}
\hline \multirow{4}{*}{$\begin{array}{l}\text { Prize for stage } \\
(\$ 1,000)\end{array}$} & \multicolumn{6}{|c|}{ Dependent Variable: Games won by an Individual Player $P$} \\
\hline & \multicolumn{4}{|c|}{ OLS: Individual Fixed Effects } & \multicolumn{2}{|c|}{ Selection Model } \\
\hline & 0.005 & & 0.006 & & 0.003 & 0.003 \\
\hline & $(0.002)^{* *}$ & & $(0.002)^{* *}$ & & $(0.007)$ & $(0.006)$ \\
\hline Total prize money & & $1.88 E^{-4}$ & & $2.07 E^{-4}$ & & \\
\hline$(\$ 1,000)$ & & $(0.001)$ & & $(0.001)$ & & \\
\hline Match is final & & 1.847 & & 1.893 & & \\
\hline & & $(0.391)^{* *}$ & & $(0.388)^{* *}$ & & \\
\hline Heterogeneity & -0.012 & -0.013 & & & -0.039 & \\
\hline (own-opponent rank) & $(0.006)^{1}$ & $(0.006)^{*}$ & & & $(0.012)^{* *}$ & \\
\hline Heterogeneity & & & 0.258 & 0.272 & & 0.584 \\
\hline (Klaassen/Magnus, 2003) & & & $(0.086)^{* *}$ & $(0.085)^{* *}$ & & $(0.140)^{* *}$ \\
\hline Constant & 118.13 & 19.04 & 4.427 & 7.490 & 13.28 & 14.10 \\
\hline & $\left((1.743)^{* *}\right.$ & $(2.624)^{* *}$ & $(1.938)^{* *}$ & $(2.282)^{*}$ & $(2.816)^{* *}$ & $(3.187)^{* *}$ \\
\hline Tournament Dummies & Yes & Yes & Yes & Yes & Yes & Yes \\
\hline Year Dummies & Yes & Yes & Yes & Yes & Yes & Yes \\
\hline Player Dummies & Yes & Yes & Yes & Yes & No & No \\
\hline \multicolumn{7}{|l|}{ Selection Equation } \\
\hline Prize for reaching final & & & & & $3.81 E^{-8}$ & $3.72 E^{-8}$ \\
\hline$(\$ 1,000)$ & & & & & $\left(4.82 E^{-7}\right)$ & $\left(4.83 E^{-7}\right)$ \\
\hline Heterogeneity (semi) & & & & & -0.007 & \\
\hline (own-opponent rank) & & & & & $(0.001)^{* *}$ & \\
\hline Heterogeneity (semi) & & & & & & 0.100 \\
\hline (Klaassen/Magnus, 2003) & & & & & & $(0.019)^{* *}$ \\
\hline \multirow[t]{2}{*}{ Constant } & & & & & -0.466 & -0.470 \\
\hline & & & & & $(0.099)^{* *}$ & $(0.100)^{* *}$ \\
\hline \multirow[t]{2}{*}{$\lambda$} & & & & & 2.786 & 0.319 \\
\hline & & & & & $(2.331)$ & $(1.863)$ \\
\hline$N$ & 920 & 920 & 920 & 920 & 920 & 920 \\
\hline Censored $N$ & & & & & 620 & 620 \\
\hline$R^{2}$ & 0.393 & 0.405 & 0.398 & 0.410 & & \\
\hline
\end{tabular}

Notes: Heterogeneity measure following Klaassen and Magnus (2003) is constructed as in footnote 21. Standard errors in parentheses, robust standard errors for OLS. ${ }^{* *}$ Coefficient significant at the 1-\%-level. ${ }^{*}$ Coefficient significant at the 5-\%-level. ${ }^{1}$ Coefficient significant at the $10-\%$-level. LR-test statistics for independence of selection and evaluation equation: $\chi^{2}(1)=1.20$ and $\chi^{2}(1)=0.03$, respectively. 


\section{IZA Discussion Papers}

\begin{tabular}{|c|c|c|c|c|}
\hline No. & Author(s) & Title & Area & Date \\
\hline 933 & $\begin{array}{l}\text { W. Arulampalam } \\
\text { A. L. Booth } \\
\text { M. L. Bryan }\end{array}$ & Training in Europe & 5 & $11 / 03$ \\
\hline 934 & $\begin{array}{l}\text { M. Piva } \\
\text { E. Santarelli } \\
\text { M. Vivarelli }\end{array}$ & $\begin{array}{l}\text { The Skill Bias Effect of Technological and } \\
\text { Organisational Change: Evidence and Policy } \\
\text { Implications }\end{array}$ & 5 & $11 / 03$ \\
\hline 935 & T. J. Dohmen & $\begin{array}{l}\text { Performance, Seniority and Wages: Formal } \\
\text { Salary Systems and Individual Earnings Profiles }\end{array}$ & 1 & $11 / 03$ \\
\hline 936 & $\begin{array}{l}\text { M. K. Jones } \\
\text { P. L. Latreille } \\
\text { P. J. Sloane }\end{array}$ & Disability, Gender and the Labour Market & 3 & $11 / 03$ \\
\hline 937 & $\begin{array}{l}\text { W. Eggert } \\
\text { L. Goerke }\end{array}$ & $\begin{array}{l}\text { Fiscal Policy, Economic Integration and } \\
\text { Unemployment }\end{array}$ & 2 & $11 / 03$ \\
\hline 938 & $\begin{array}{l}\text { D. Del Boca } \\
\text { A. Venturini }\end{array}$ & Italian Migration & 1 & $11 / 03$ \\
\hline 939 & E. Toulemonde & $\begin{array}{l}\text { Acquisition of Skills, Education Subsidies, and } \\
\text { Agglomeration of Firms }\end{array}$ & 2 & $11 / 03$ \\
\hline 940 & $\begin{array}{l}\text { A. Constant } \\
\text { Y. Shachmurove } \\
\text { K. F. Zimmermann }\end{array}$ & $\begin{array}{l}\text { What Makes an Entrepreneur and Does It Pay? } \\
\text { Native Men, Turks, and Other Migrants in } \\
\text { Germany }\end{array}$ & 1 & $11 / 03$ \\
\hline 941 & $\begin{array}{l}\text { R. V. Burkhauser } \\
\text { J. S. Butler } \\
\text { G. Gumus }\end{array}$ & $\begin{array}{l}\text { Option Value and Dynamic Programming Model } \\
\text { Estimates of Social Security Disability Insurance } \\
\text { Application Timing }\end{array}$ & 6 & $11 / 03$ \\
\hline 942 & $\begin{array}{l}\text { R. V. Burkhauser } \\
\text { J. S. Butler } \\
\text { G. Gumus }\end{array}$ & $\begin{array}{l}\text { Dynamic Modeling of the SSDI Application } \\
\text { Timing Decision: The Importance of Policy } \\
\text { Variables }\end{array}$ & 6 & $11 / 03$ \\
\hline 943 & $\begin{array}{l}\text { J. T. Addison } \\
\text { P. Teixeira }\end{array}$ & $\begin{array}{l}\text { What Have We Learned About the Employment } \\
\text { Effects of Severance Pay? Further Iterations of } \\
\text { Lazear et al. }\end{array}$ & 3 & $11 / 03$ \\
\hline 944 & $\begin{array}{l}\text { H. Görg } \\
\text { D. Greenaway }\end{array}$ & $\begin{array}{l}\text { Much Ado About Nothing? Do Domestic Firms } \\
\text { Really Benefit from Foreign Direct Investment? }\end{array}$ & 2 & $11 / 03$ \\
\hline 945 & $\begin{array}{l}\text { R. Schöb } \\
\text { D. E. Wildasin }\end{array}$ & $\begin{array}{l}\text { Economic Integration and Labor Market } \\
\text { Institutions: Worker Mobility, Earnings Risk, and } \\
\text { Contract Structure }\end{array}$ & 2 & $12 / 03$ \\
\hline 946 & M. Leonardi & $\begin{array}{l}\text { Earnings Instability of Job Stayers and Job } \\
\text { Changers }\end{array}$ & 1 & $12 / 03$ \\
\hline 947 & U. Sunde & $\begin{array}{l}\text { Potential, Prizes and Performance: Testing } \\
\text { Tournament Theory with Professional Tennis } \\
\text { Data }\end{array}$ & 7 & $12 / 03$ \\
\hline
\end{tabular}

An updated list of IZA Discussion Papers is available on the center's homepage www.iza.org. 